\title{
DAMPAK PENYELENGGARAAN EVENT PARIWISATA DRAGON BOAT RACE DI KOTA TANJUNGPINANG
}

\author{
Ida Rahayu \\ Prodi Magister Kajian Pariwisata Universitas Udayana \\ Email: rahayumanaf@rocketmail.com
}

\begin{abstract}
The development of the Dragon Boat Race tourism event was adopted from the religious activities of the Chinese community in Tanjungpinang City will indirectly generate an impact as a consequence of its implementation. This study aims to determine the impacts generated by the Dragon Boat Race Event on environmental, socio-cultural and economic aspects. This research used qualitative method and data obtained through observations, interviews and literature study. Data analysis used is descriptive-qualitative with qualitative descriptive exposure. Informants in this study are 16 people whom were selected purposively. The results show that the impact of the event of Dragon Boat Race tourism in general has some positive snd negative impacts. Positive impacts on the environment is the opening of the land; on the social and cultural is the creation of social interaction and international relations; and positive impact on the economy is increasing income and providing employment opportunities. Negative impacts on the environment is traffic density and noise created around the Carang River area; on the social and cultural is social disparities between local communities, government and private parties. This gap occurs because of differences in social status between them; on the economy is uneven benefits and profits for local communities since not many people aware of the importance of their participation in Dragon Boat Race
\end{abstract}

Keywords: Tourism event, sport tourism, impact.

\section{Pendahuluan}

Salah satu event pariwisata tahunan yang cukup populer di Kota Tanjungpinang, Provinsi Kepulauan Riau, adalah Dragon 
Boat Race atau lomba perahu naga. Secara teknis, Dragon Boat Race adalah lomba yang dilakukan secara berkelompok/tim dalam mendayung perahu yang berbentuk mirip seekor naga. Peserta dalam setiap tim harus mendayung dengan secepat mungkin agar perahu sampai di garis finish lebih awal dari tim lawan. Dragon Boat Race merupakan event turun temurun milik leluhur bangsa Cina yang sudah digelar sejak ratusan tahun yang lalu. Akan tetapi, munculnya Dragon Boat Race di Kota Tanjungpinang baru dimulai pada tahun 1952 yang digelar oleh masyarakat Tionghoa untuk ritual keagamaan. Pada umumnya masyarakat Tionghoa di Kota Tanjungpinang juga mengenal ritual keagamaan Dragon Boat Race dengan nama lain yaitu 'Sembahyang Keselamatan Laut'.

Pada tahun 1992, event tradisional ini diduplikasi oleh Pemerintah Daerah setempat untuk dijadikan sebagai atraksi wisata. Event ini dianggap memiliki daya tarik yang bisa mendatangkan wisatawan ke Kota Tanjungpinang. Hal tersebut sesuai dengan pendapat Getz (1991) yang mengatakan bahwa aspek penting dari penyelenggaraan event adalah upaya untuk mendatangkan wisatawan baik domestik maupun mancanegara. Mulai tahun 2002, event pariwisata Dragon Boat Race dikelola oleh Dinas Pariwisata dan Kebudayaan Kota Tanjungpinang. Hingga saat ini, Dragon Boat Race masih terus digelar setiap satu tahun sekali selama tiga hari. Event ini juga sudah masuk dalam kalender event pariwisata resmi Pemerintah Kota Tanjungpinang dan Pemerintah Provinsi Kepulauan Riau.

Penelitian ini dilakukan berdasarkan pemikiran bahwa meski waktu pelaksanaannya tergolong singkat, tetapi penyelenggaraan event tidak bisa dihindarkan dari dampak yang bisa muncul dari faktor lingkungan, sosial budaya dan ekonomi dan bisa bersifat positif atau negatif. Seperti yang dinyatakan oleh Pitana dan Gayatri (2005) bahwa jika suatu daya tarik wisata tidak dikelola dan ditangani dengan baik atau tidak direncanakan dengan matang maka akan memberikan dampak yang negatif. Sejak awal penyelenggaraannya, Dragon Boat Race memiliki potensi besar terhadap peningkatan jumlah kunjungan wisatawan karena melibatkan banyak peserta yang berasal dari 
luar daerah dan luar negeri. Hal ini juga menjadi peluang bagi masyarakat untuk meraup keuntungan dengan membuka usaha makanan, minuman, transportasi tradisional dan lain sebagainya.

Selain itu, event ini juga dapat menambah peningkatan PAD. Oleh karena itu, Dinas Pariwisata dan Kebudayaan Kota Tanjungpinang sebagai penyelenggara wajib mengatur dan mengelola event dengan sebaik mungkin agar dapat memberikan manfaat yang positif. Sesuai dengan Undang-Undang Nomor 10 tahun 2009 tentang Kepariwisataan Pasal 23 yang mengatakan bahwa Pemerintah dan Pemerintah Daerah wajib mengawasi dan mengendalikan kegiatan Kepariwisataan dalam rangka mencegah dan menanggulangi berbagai dampak negatif bagi masyarakat luas. Jika event ini tidak memberikan dampak yang positif bagi daerah dan masyarakat, maka diperlukan sebuah solusi agar permasalahan-permasalahan yang muncul dapat diselesaikan.

\section{Teori dan Metode}

Menurut Getz (1991), event mempunyai peran penting dalam pembangunan pariwisata. Peran penting ini diperlukan karena Dragon Boat Race tidak hanya menjadi sebuah daya tarik pariwisata tetapi juga menjadi sebuah ajang kompetisi bergengsi dalam cabang olahraga dayung bertaraf internasional di Kota Tanjungpinang. Murphy (1997:76) berpendapat bahwa event olahraga akan melibatkan banyak pihak sehingga tuan rumah dapat mengambil keuntungan sebagai strategi pengembangan daerah. Keuntungan ini bisa didapatkan dari beberapa faktor seperti penjualan barang konsumsi, hunian kamar, transportasi, objek wisata yang ada disekitar kawasan/kota tempat diselenggarakan event, penjualan merchandise serta lapangan kerja.

Selain itu, daerah penyelenggara event juga berpotensi untuk menjadi tuan rumah dalam event-event lainnya serta dapat menumbuhkan minat dan bakat generasi muda terhadap cabang olahraga yang digelar sehingga memunculkan bibit-bibit olahragawan yang baru. Pop, et al. (2016) menambahkan bahwa besar kecilnya keuntungan yang bisa didapat sangat bergantung pada skala event, lama penyelenggaraan dan jumlah penonton 
yang datang dari luar daerah dan luar negeri. Penelitian ini akan merujuk kepada beberapa penelitian sebelumnya tentang dampak event pariwisata dan event olahraga yang dilakukan oleh Maulana (2013), Mohammad (2014), Luna (2015), Marpaung (2015), Wirawan (2015) dan Santos, dkk. (2017).

Teori yang digunakan dalam penelitian ini adalah teori dampak. Dampak secara sederhana dapat diartikan sebagai pengaruh atau akibat sedangkan dampak pariwisata dapat diartikan sebagai akibat yang dihasilkan oleh kegiatan pariwisata. Dickman (1992) mengatakan bahwa dampak pariwisata adalah konsekuensi dari sebuah kegiatan pariwisata yang berkembang sehingga menimbulkan berbagai dampak baik itu positif maupun negatif. Berbeda dengan Dickman, menurut Fredline dkk. (2003) dampak event adalah efek dan segala hal yang timbul yang dapat merubah kualitas hidup masyarakat lokal serta cara pandang atau bersikap masyarakat terhadap event tersebut. Mill (2000:168169) membedakan dampak pariwisata dalam beberapa aspek yang terdiri dari dampak terhadap kondisi lingkungan, dampak terhadap sosial budaya dan dampak terhadap ekonomi.

Penelitian ini menggunakan metode kualitatif dengan pengamatan (survei dan observasi), wawancara mendalam dan studi pustaka. Penelitian ini dibuat untuk mengetahui dampak dari penyelenggaraan event pariwisata Dragon Boat Race di Kota Tanjungpinang yang akan dibagi dalam tiga aspek yakni dampak terhadap lingkungan, sosial budaya dan ekonomi. Informasi diperoleh melalui pengamatan langsung, wawancara secara mendalam, studi literatur dan studi dokumentasi. Sementara itu, data akan disajikan dalam bentuk naratif menggunakan analisis deskriptif-kualitatif. Informan dalam penelitian ini dipilih secara purposif dengan jumlah sebanyak 16 orang yang berasal dari pemerintah, pelaku usaha dan masyarakat yang berkaitan dengan penyelenggaraan Dragon Boat Race Event.

\section{Sejarah dan Perkembangan Dragon Boat Race Sejarah Dragon Boat Race}

Dragon Boat Race atau lomba perahu naga di kalangan 
masyarakat Tionghoa secara global memiliki nama lain yang juga dikenal dengan nama Duan-Wu. Event ini diselenggarakan setiap satu tahun sekali di hari kelima pada bulan kelima dalam perhitungan kalender Cina. Ada tiga cerita berbeda yang diterima secara luas oleh masyarakat Tionghoa tentang asal usul yang berhubungan dengan event Dragon Boat Race (Chinesepod, 2017). Akan tetapi asal usul Dragon Boat Race yang paling berpengaruh dan paling populer hingga kalangan internasional seperti saat ini adalah cerita yang dikaitkan dengan seorang tokoh patriotic dari Cina yang bernama Qu Yuan.

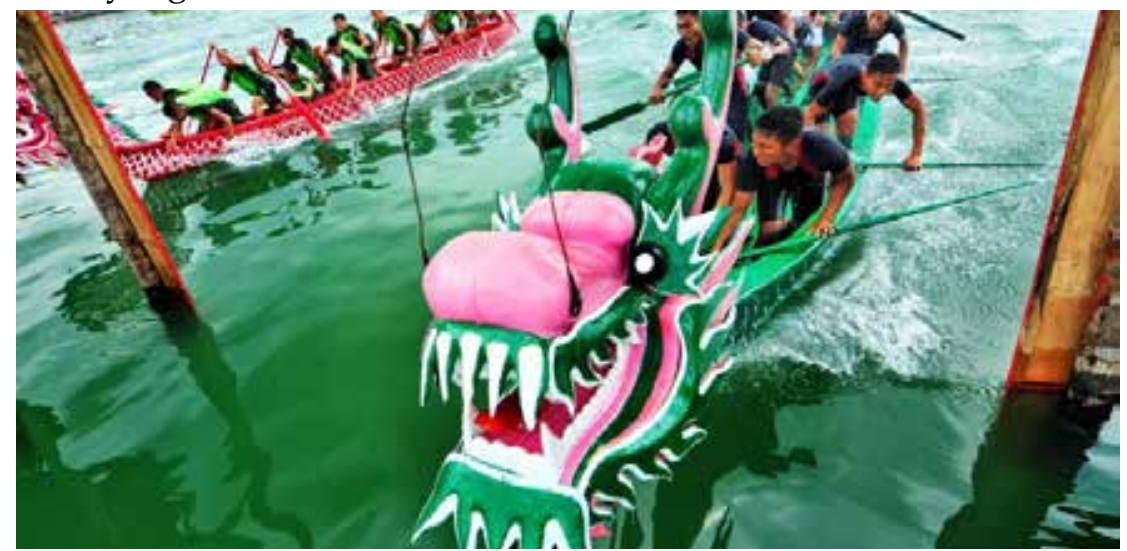

Foto 1: Dragon Boat Race di Tanjungpinang

Sumber: (https://sumber.com/component/k2/sumber/dragon-boat-race, event- balapan-naga-air-tahunan-kota-tanjung-pinang.html

Cerita tersebut sejalan dengan penjelasan dari Bapak Minarso selaku Ketua RT 03 Kelurahan Tanjungpinang Kota dalam wawancaranya bersama penulis yang mengatakan bahwa penyelenggaraan Dragon Boat Race atau ritual keagamaan 'Sembahyang Keselamatan Laut' yang dilakukan oleh masyarakat Tionghoa Kota Tanjungpinang sejak tahun 1952 bertujuan untuk mengenang sosok negarawan dari Kerajaan Chu (475-221 SM) yang bernama Qu Yuan. Qu Yuan sangat dihormati dan dicintai oleh rakyat karena memiliki kejujuran yang tinggi dan sikap patriotnya dalam memperjuangkan kesejahteraan rakyat.

Pada tahun 278 SM Qu Yuan bunuh diri dengan cara menenggelamkan diri ke Sungai Miluo sambil memeluk sebuah 
batu besar di dadanya. Hal ini dilakukan sebagai bentuk kekecewaannya terhadap kepemimpinan Raja Chu yang karena tidak bisa menyelamatkan Kerajaan Chu dari kehancuran. Saat mendengar kabar kematian Qu Yuan, seluruh rakyat Chu bergegas mendatangi Sungai Miluo dengan perahu untuk mencari jasad sang negarawan. Rakyat Chu juga melemparkan nasi dan bakcang serta menepuk-nepuk dayung di permukaan air Sungai Miluo dengan keras agar ikan-ikan dan makhluk hidup yang ada di sungai tidak merusak dan memakan jasad Qu Yuan. Banyaknya perahu dan orang yang berkumpul di Sungai Miluo untuk menyelamatkan jasad Qu Yuan inilah yang kemudian dipercaya oleh sebagian besar masyarakat Tionghoa sebagai asal usul penyelenggaraan Dragon Boat Race.

SaatinidiKotaTanjungpinang terdapatdua penyelenggaraan Dragon Boat Race. Dragon Boat Race yang pertama dikelola oleh Yayasan Vihara Cetiya Bodhi dan digelar secara tertutup untuk kegiatan tradisional keagamaan masyarakat Tionghoa, sedangkan Dragon Boat Race yang kedua dikelola oleh Dinas Pariwisata dan Kebudayaan Kota Tanjungpinang secara terbuka sebagai event pariwisata. Masuknya Dragon Boat Race ke Kota Tanjungpinang bermula dari interaksi yang terjadi antara masyarakat Melayu sebagai penduduk asli Kota Tanjungpinang dengan para pendatang dari Negeri Cina. Sebagai bentuk penghargaan kepada masyarakat asli Kota Tanjungpinang, masyarakat Tionghoa akhirnya mengenalkan lomba perahu tradisional Dragon Boat Race atau tradisi 'Sembahyang Keselamatan Laut' yang saat ini masih terus berlangsung.

\section{Perkembangan Dragon Boat Race Event di Kota Tanjungpinang}

Mulai tahun 2002 event ini diambil alih oleh Pemerintah Kota Tanjungpinang setelah sebelumnya dikelola oleh Pemerintah Kabupaten Kepulauan Riau (sekarang bernama Kabupaten Bintan). Berkembangnya kawasan Provinsi Kepulauan Riau dan terpilihnya Kota Tanjungpinang sebagai pusat Pemerintahan turut memberikan perkembangan positif terhadap Dragon Boat Race. Sejauh ini penyelenggaraan Dragon Boat Race sudah 
mengalami beberapa perubahan yang positif. Perkembangan ini dimulai dari skala event yang awalnya hanya digelar untuk masyarakat lokal kemudian berkembang menjadi event berskala nasional. Perkembangan juga terjadi pada standar perlombaan yang dimulai dengan menggunakan standar tradisional dan telah diangkat menjadi berstandar internasional. Standar internasional ini telah diatur secara resmi oleh lembaga khusus cabang olahraga dayung perahu naga tingkat internasional. Perkembangan juga terjadi pada lokasi pelaksanaan event yang sebelumnya terletak di perairan laut pelabuhan domestik di pusat kota hingga dipindahkan ke Sungai Carang.

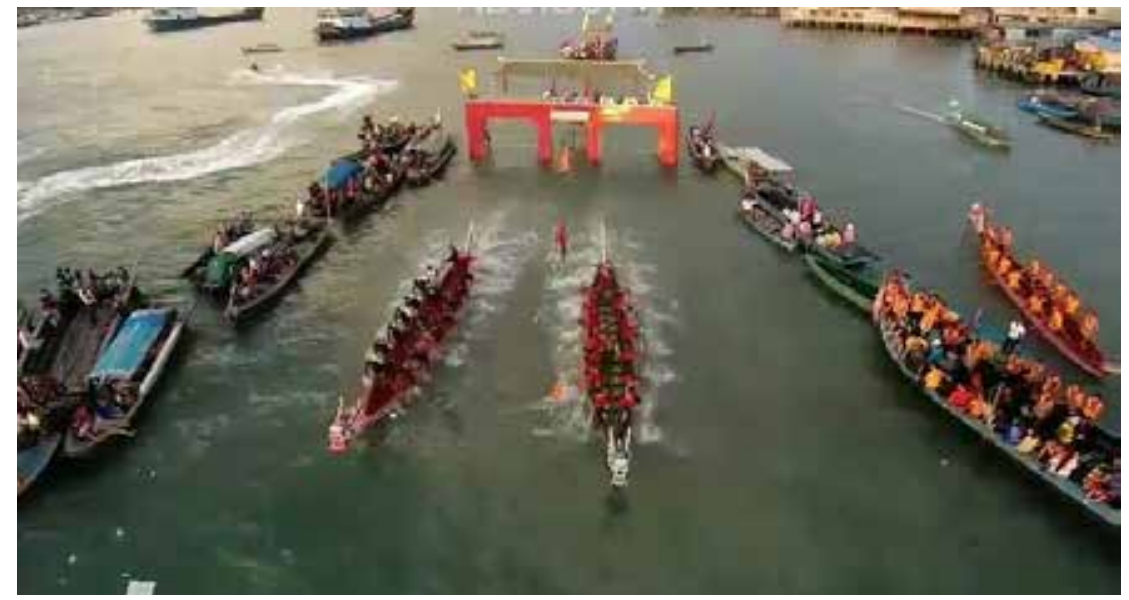

Foto 2: Suasana Dragon Boat Race di Tanjungpinang

Sumber:https:/gurindam.tv/25-tahun-sejarah-dragon-boat-tanjungpinang/

Selama menjadi event pariwisata berskala nasional, Dragon Boat Race telah mendatangkan tim-tim yang berasal dari berbagai daerah di Indonesia seperti Riau, Sumatera, Kalimantan dan Jawa. Bahkan tim peserta Dragon Boat Race di Kota Tanjungpinang juga berasal dari luar negeri seperti Malaysia, Brunei Darussalam, Singapura dan Republik Ceko. Selain mengadakan perlombaan perahu naga sebagai daya tarik utama, event ini juga diselingi dengan kegiatan seperti perlombaan kayak/kano, pameran, bazar dan penjualan makanan dan minuman. Penyelenggaraan Dragon Boat Race yang dikelola oleh Pemerintah Kota Tanjungpinang sejak tahun 2002 hingga tahun 2013 memiliki perbedaan dengan 
kompetisi olahraga Dragon Boat Race resmi pada umumnya. Pada periode tersebut, event ini masih mengikuti aturan tradisional seperti kegiatan 'Sembahyang Keselamatan Laut' yang dilakukan oleh masyarakat Tionghoa.

Akan tetapi, pindahnya lokasi penyelenggaraan Dragon Boat Race ke Sungai Carang pada tahun 2014 juga telah merubah teknis pelaksanaan event. Penyelenggaraan ini sudah disesuaikan dengan standar internasional perlombaan perahu naga yang diatur oleh IDBF (Internasional Dragon Boat Race Federation). Secara spesifik, perbedaan event setelah berstandar internasional terletak pada bentuk perahu, jumlah peserta dalam setiap tim, gaya mendayung dan jalur yang ditempuh. Hadiah yang diberikan kepada pemenang Dragon Boat Race bernilai hingga ratusan juta rupiah. Selain mendapatkan uang tunai, para pemenang juga akan mendapatkan piala Dragon Boat Race yang diberikan oleh Walikota Tanjungpinang dan piala bergilir yang diberikan oleh Gubernur Provinsi Kepulauan Riau yang diberikan kepada juara bertahan.

\section{Faktor Pendukung dan Penghambat Penyelenggaraan Dragon} Boat Race

\section{Faktor Pendukung}

\section{Dukungan dari Stakeholder}

Faktor pendukung penyelenggaraan Dragon Boat Race berasal dari stakeholder seperti instansi/lembaga vertikal, masyarakat dan pelaku usaha. SKPD (Satuan Perangkat Kerja Daerah) memberikan dukungan dengan menjalankan tugas dan fungsi masing-masing instansi seperti mengatur dan bertanggungjawab terhadap kebersihan, keamanan, ketertiban dan keselamatan para peserta di lokasi event. Beberapa instansi yang turut terlibat dalam event ini diantaranya adalah Dinas Kesehatan, Dinas Perhubungan, Dinas Pendidikan dan Olahraga, Dinas Koperasi dan UKM, Dinas Kebersihan, Badan Penanggulangan Bencana Daerah (BPBD), Satuan Polisi Pamong Praja (Satpol PP), Kepolisian, dan Persatuan Olahraga Dayung Seluruh Indonesia (PODSI) cabang Kota Tanjungpinang. 
Pariwisata di Kota Tanjungpinang secara garis besar telah ditunjang oleh sarana dan prasarana yang baik mulai dari akomodasi, transportasi, aksesibilitas, dan hingga atraksi wisata yang beragam. Untukdapatmemenuhi kebutuhan dan pendukung pariwisata, di kawasan wisata harus disediakan berbagai fasilitas yang berhubungan dengan pariwisata. Dukungan dari pihak swasta dijelaskan oleh Ibu Lina, Bapak Hendro dan Bapak Zainuddin yang berasal dari pihak penyedia sarana akomodasi dan Ibu Mega sebagai pelaku usaha yang telah mendapatkan informasi terkait dengan penyelenggaraan kegiatan pariwisata sehingga pihak ini dapat memaksimalkan sumber daya yang mereka miliki untuk mempermudah wisatawan dari luar daerah dan luar negeri yang datang ke Kota Tanjungpinang.

Sementara itu, dukungan dari masyarakat ditunjukkan dengan beberapa cara seperti Bapak Ramli yang membentuk kelompok pemuda lokal untuk membantu panitia menjaga keamanan dan ketertiban. Bentuk dukungan dari masyarakat juga ditunjukkan oleh Ibu Ramty Ramadita yang membuka warung di lokasi event. Beberapa masyarakat lainnya juga berpartisipasi dengan berjualan es krim, roti, buah potong, mainan anak, makanan ringan, minuman botol dan sebagainya. Meski Dragon Boat Race melibatkan peserta dari luar daerah dan luar negeri, masyarakat Kota Tanjungpinang yang memiliki hobi dan bakat dalam bidang olahraga dayung tidak kalah antusias untuk menjadi peserta. Bahkan beberapa tim lokal berpartisipasi dalam event ini merupakan tim perwakilan dari masyarakat Tionghoa. Seperti yang telah dijelaskan oleh Bapak Minarso bahwa penyelenggaraan Dragon Boat Race yang dikelola oleh Pemerintah tidak menimbulkan rasa keberatan dari kalangan masyarakat Tionghoa. Sebaliknya, justru masyarakat tersebut merasa sangat bangga karena tradisi leluhurnya turut dilestarikan dan diangkat menjadi event resmi seperti sekarang.

\section{Juri dan Wasit Berlisensi Nasional}

Faktor pendukung penyelenggaraan Dragon Boat Race juga berasal dari pemilihan wasit/juri lomba. Sebelum ditetapkan 
menjadi event nasional seperti sekarang wasit/juri yang digunakan dalam event ini berasal dari lembaga olahraga dayung lokal. Akan tetapi sejak penyelenggaraan event nasional ini dirubah sesuai dengan standar peraturan internasional, maka juri/wasit yang digunakan juga merupakan wasit tingkat nasional tingkat PON dan PORPROV.

Peminat Event yang Cukup Banyak dan Objek Wisata di Sungai Carang

Penyelenggaraan Dragon Boat Race secara tidak langsung telah menawarkan atraksi pariwisata yang berbeda dari objek wisata pada umumnya. Oleh karena itu, tidak heran jika selama penyelenggaraannya event ini menghadirkan berbagai peserta dan penonton yang berasal dari luar daerah dan luar negeri. Jika pada awal penyelenggaraannya event ini hanya diikuti oleh beberapa tim lokal, maka pada penyelenggaraan tingkat nasional saat ini jumlah peserta event sudah mencapai 40 tim. Selain itu, di sekitar kawasan Sungai Carang yang menjadi lokasi baru penyelenggaraan Dragon Boat Race terdapat beberapa objek wisata sejarah Kerajaan Melayu Riau yang bisa dikunjungi oleh penonton seperti Situs Cagar Budaya Istana Kota Rebah, Makam Bangsawan Bugis dan Hutan Bakau.

\section{Faktor Penghambat}

Kurangnya Fasilitas Pariwisata di Sungai Carang

Faktor penghambat penyelenggaraan Dragon Boat Race di Kota Tanjungpinang adalah kurangnya fasilitas penunjang kegiatan pariwisata di Sungai Carang. Para penonton yang datang dari luar daerah hanya dapat menemukan hotel/penginapan, rumah makan, pusat perbelanjaan di kawasan pusat kota. Padahal pembangunan fasilitas pendukung yang dekat dengan lokasi sangat diperlukan agar penonton/pengunjung dapat menyaksikan event dengan nyaman. Selain itu, beberapa titik rawan yang mengancam keselamatan para penonton/pengunjung justru dijadikan sebagai tempat menonton seperti pinggiran sungai, di atas jembatan dan dermaga ponton. Tindakan seperti ini sangat beresiko bagi masyarakat/penonton karena dapat menimbulkan 
hal yang tidak diinginkan.

\section{Kepemilikan Lahan di Sungai Carang}

Masalah kepemilikan lahan merupakan salah satu faktor penghambat penyelenggaraan Dragon Boat Race Event di Kota Tanjungpinang. Lokasi yang digunakan untuk penyelenggaraan Dragon Boat Race di Sungai Carang bukan milik Pemerintah sehingga panitia harus meminta izin terlebih dahulu kepada pemilik lahan setiap kali akan menggelar event. Permasalahan lahan ini dapat menimbulkan ancaman terhadap penolakan perizinan oleh pemilik lahan yang sewaktu-waktu bisa saja terjadi.

\section{Kepemilikan Perahu Dragon Boat Race}

Hal lain yang menjadi faktor penghambat penyelenggaraan Dragon Boat Race adalah terkait masalah kepemilikan perahu naga sejak event dirubah menjadi berstandar internasional. Sebelum menjadi event berstandar internasional seperti sekarang, perahu yang digunakan pada event ini memiliki kesamaan pada perahu untuk event tradisional masyarakat Tionghoa. Karena saat ini Pemerintah Kota Tanjungpinang belum memiliki perahu naga berstandar internasional maka panitia terpaksa menyewa/ meminjam perahu berstandar internasional dari pihak lain.

\section{Dampak Event Pariwisata Dragon Boat Race di Kota Tanjungpinang \\ Dampak terhadap Lingkungan}

Dampak penyelenggaraan Dragon Boat Race terhadap lingkungan yang bersifat positif adalah pembukaan lahan di sekitar Sungai Carang. Sebelum digunakan sebagai lokasi penyelenggaraan Dragon Boat Race, kawasan ini dahulunya masih berupa hutan-hutan. Hal ini dapat dikategorikan sebagai dampak positif karena lahan yang digunakan untuk event hanya sebagian kecil sehingga aktivitas event tidak merusak dan mengganggu ekosistem yang ada di kawasan Sungai Carang. Sungai Carang sering digunakan oleh masyarakat untuk memancing dan dijadikan sebagai jalur lalu-lintas perahu tradisional nelayan 
sehingga kebersihan alam dikawasan ini tetap terjaga. Meski aktivitas event tidak menyebabkan dampak negatif yang besar terhadap kondisi lingkungan, namun bukan berarti dampak negatif tersebut tidak terjadi. Dampak negatif yang dihasilkan oleh event tersebut sangat kecil dan berlangsung dalam jangka waktu yang singkat seperti kepadatan lalu lintas dan kebisingan yang tercipta di sekitar kawasan Sungai Carang. Akan tetapi, setelah event selesai digelar, kondisi lingkungan di Sungai Carang akan kembali normal dan stabil.

\section{Dampak terhadap Sosial Budaya}

Dampak penyelenggaraan Dragon Boat Race terhadap sosial budaya terjadi setelah event dipindahkan ke Sungai Carang yang berada di perbatasan antara Kota Tanjungpinang dan Kabupaten Bintan. Selama ini masyarakat hanya terfokus pada destinasi yang ada di pusat kota sehingga interaksi antara keduanya jarang terjadi. Penyelenggaraan Dragon Boat Race di Sungai Carang telah menyebabkan terjadinya interaksi antara kedua masyarakat dan juga antara Kota Tanjungpinang dengan beberapa Negara yang menjadi peserta event. Meski pada dasarnya event ini adalah sebuah kompetisi olahraga, namun melalui kegiatan ini dapat terjalin persahabatan dan persaudaraan antara Tanjungpinang sebagai penyelenggara dengan Negara yang terlibat. Pemeliharaan hubungan internasional yang baik antara masyarakat dan wisatawan dapat menumbuhkan rasa pengertian terhadap perbedaan dan juga menumbuhkan rasa saling menghormati meskipun sedang berada dalam sebuah kompetisi. Dampak positif penyelenggaraan Dragon Boat Race juga ditunjukkan dengan kehadiran event ini sebagai wadah untuk menampung bakat para atlet dayung yang berasal dari dalam daerah dan sekaligus menjadi peluang besar bagi Pemerintah untuk memunculkan bibit-bibit baru dalam bidang olahraga dayung.

Sementara itu, dampak negatif terhadap sosial budaya yang muncul adalah permasalahan kesenjangan sosial antara masyarakat lokal, Pemerintah dan pihak swasta. Kesenjangan ini terjadi karena adanya perbedaan status sosial antara Pemerintah, 
pihak swasta dan pelaku usaha. Masyarakat berada di posisi lebih rendah jika dibandingkan dengan Pemerintah dan pihak swasta yang status sosialnya lebih tinggi. Hal ini disampaikan oleh Bapak Hamizan yang menilai bahwa secara umum jumlah masyarakat yang turut dilibatkan dalam penyelenggaraan Dragon Boat Race belum terlalu banyak. Rapat persiapan penyelenggaraan event juga tidak menyertakan masyarakat sebagai salah satu stakeholder sehingga informasi penting seperti kesempatankesempatan besar yang bisa dilakukan masyarakat dalam event ini tidak tersampaikan dengan menyeluruh. Pendapat ini juga diperkuat oleh pernyataan Bapak Said Afzaldy bahwa kegiatan ini terkesan hanya bertujuan untuk memberikan keuntungan terhadap Pemerintah Daerah dan pelaku usaha. Padahal sebagian masyarakat lainnya bisa saja terlibat dalam tindakan yang lebih luas asal diberikan informasi yang jelas.

\section{Dampak terhadap Ekonomi}

Dampak positif dari penyelenggaraan Dragon Boat Race terhadap ekonomi adalah peningkatkan pendapatan yang dirasakan oleh Ibu Ratnawati seorang penjual makanan yang menerima orderan katering makan siang dan makan malam untuk beberapa tim yang berasal dari Jambi selama mengikuti event. Selain Ibu Ratnawati, peningkatan pendapatan juga dirasakan oleh Bapak Daeng Mangendrek seorang penambang perahu yang diminta oleh panitia untuk mendampingi juri menyusuri perairan Sungai Carang selama event berlangsung. Selama Dragon Boat Race berlangsung, pendapatan yang diterima oleh Ibu Ratnawati dan Bapak Daeng Mangendrek lebih banyak daripada hari biasa.

Selain dirasakan oleh masyarakat, dampak ekonomi terhadap peningkatan pendapatan juga disampaikan oleh pihak swasta yakni Bapak Hendro dan Bapak Zainuddin yang bekerja sebagai Manager Hotel di Kota Tanjungpinang. Bapak Hendro dan Bapak Zainuddin menyetujui bahwa penyelenggaraan Dragon Boat Race telah menyebabkan kenaikan jumlah tamu yang menginap meskip event berlangsung dalam waktu yang singkat. Pendapat tersebut juga diperkuat oleh Ibu Mega yang berjualan produk kosmetik 
dan skin care dengan membuka stan di lokasi penyelenggaraan event di Sungai Carang selama 3 hari.

Selain itu, dampak positif terhadap ekonomi juga terjadi melalui kesempatan kerja yang dirasakan oleh Ibu Ramty Ramadita. Sehari-harinya Ibu Ramty Ramadita tidak bekerja dan hanya menjadi ibu rumah tangga yang fokus mengurus anak. Namun saat mengetahui akan ada penyelenggaraan Dragon Boat Race di Sungai Carang yang berada dekat dengan rumahnya, Ibu Ramty Ramadita langsung berinisiatif untuk membuka warung kecil selama event berlangsung.

Dampak negatif ekonomi terhadap penyelenggaraan Dragon Boat Race di Kota Tanjungpinang adalah manfaat dan keuntungan yang belum merata bagi masyarakat lokal. Belum banyak masyarakat yang mengetahui pentingnya partisipasi mereka dalam kegiatan seperti Dragon Boat Race yang bisa meningkatkan pendapatan dan kesempatan kerja. Hal ini dapat terjadi karena kurangnya sosialisasi yang diberikan kepada masyarakat terhadap manfaat yang bisa didapatkan dari penyelenggaraan event sehingga manfaat eknomi hanya bisa dirasakan oleh kaum tertentu.

\section{Kesimpulan dan Saran}

Berdasarkan penjelasan yang telah diuraikan sebelumnya, dapat disimpulkan bahwa penyelenggaraan event pariwisata Dragon Boat Race di Kota Tanjungpinang sebagai daya tarik wisata telah berhasil menciptakan hiburan baru bagi pariwisata daerah yang selama ini hanya terfokus pada objek wisata pantai. Selain berkembang menjadi event bertaraf internasional yang melibatkan banyak peserta dari dalam dan luar negeri, Dragon Boat Race juga telah menciptakan citra yang baik bagi Kota Tanjungpinang di mata peminatnya. Sejauh ini penyelenggaraan Dragon Boat Race telah memberikan banyak dampak positif jika dibandingkan dengan dampak negatif. Dampak positif ini dapat terjadi pada ketiga sektor mulai dari dampak terhadap lingkungan, sosial budaya dan ekonomi. Faktor pendukung penyelenggaraan Dragon Boat Race juga menjadi kekuatan yang dimiliki oleh Dinas 
Pariwisata dan Kebudayaan untuk terus konsisten menggelar event tahunan ini. Agar dapat memaksimalkan manfaat positif dan menghindari dampak negatif, Dinas Pariwisata dan Kebudayaan Kota Tanjungpinang selaku panitia penyelenggara bersama pihak-pihak yang terlibat harus segera mengambil langkah agar faktor yang menjadi penghambat penyelenggaraan Dragon Boat Race bisa segera diatasi.

Dinas Pariwisata dan Kebudayaan Kota Tanjungpinang selaku panitia perlu memberikan informasi secara transparan kepada masyarakat luas tentang penyelenggaraan Dragon Boat Race sehingga akan lebih banyak keuntungan yang bisa diperoleh masyarakat dari event ini. Sebagian besar masyarakat banyak yang belum mengetahui manfaat dari kegiatan ini bagi kehidupannya sehingga masyarakat terksesan seolaholah sangat 'cuek'. Untuk mencapai hal ini Pemerintah Kota Tanjungpinang bisa memperbanyak pertemuan-pertemuan dan FGD yang mengikutsertakan masyarakat lokal sehingga informasi tentang kegiatan Pemerintah akan dapat tersebar dengan merata. Masyarakat juga diharapkan agar bisa membuka diri atau membentuk sebuah kelompok sadar wisata yang resmi sehingga sasaran utama dari kegiatan pariwisata yakni untuk mensejahterakan masyarakat dapat terlaksana. Melalaui organisasi yang terstruktur sekiranya akan membuat masyarakat secara keseluruhan dapat terangkul dengan pasti oleh programprogram yang dibuat oleh Pemerintah Kota Tanjungpinang.

\section{Daftar Pustaka}

Chinesepod. 2017. "Celebrating The Dragon Boat Festival in China", Sumber: https://chinesepod.com/blog/2017/06/08/celebrating-dragon-boatfestival-china/. Diakses 02/08/2017.

Dickman, S. 1992. Tourism: An Introductory Text. London: Edward Arnold.

Fredline, L., Jago, L., dan Deery, M. 2003. 'The Development of A Generic Scale To Measure The Social Impacts of Events', Event Management. Vol. 8, No. 1, pp. 23-37.

Getz, D. 1991. Festivals, Special Events, and Tourism. New York: Van Nostrand Reinhold. 
Luna, A.M. 2015. 'A Festival's Impact: The Case of The Bañamos Festival', Journal of Arts, Science E Commerce, Vol.- VI, pp. 49-58.

Marpaung, Y.K. 2015. 'Dampak Penyelenggaraan Event Piala Eropa 2012 (UEFA EURO) Terhadap Ekonomi dan Politik Ukraina', Jurnal Online Mahasiswa Fisip, Vol. 2, No.2, pp. 1-11.

Maulana, A. 2013. ‘Dampak Penyelenggaraan Tour De Singkarak Bagi Masyarakat Lokal Provinsi Sumatera Barat', Jurnal Kepariwisataan Indonesia. Vol. 8, No. 2, pp. 159-171.

Mill, R.C. 2000. The Tourism, International Business. (Tri Budi Sastrio, Pentj). Jakarta : RajaGrafindo Persada.

Mohammad, B.A. 2014. 'Festival Tourism in Saudi Arabia: A Study of Image and Motivation of Participating in Janadriyah Festival', American Journal of Tourism Management, Vol. 3, No.2, pp. 45-54.

Murphy, P.E. 1997. Quality Management in Urban Tourism. Canada: University of Victoria.

Pitana, I.G., Gayatri, P G. 2005. Sosiologi Pariwisata. Yogyakarta: Andi.

Pop, I., Kanovici, A., Ghic, G., Andrei, M. 2016. 'The Economic Effects of the Mega Sport Events on Tourism in the BRICS Countries Case', Journal of Amfiteatru Economic, Vol. 18, No. 10, pp. 960-975.

Santos, J.F, Vareiro, L., Remoaldo, P., Ribeiro, J.C. 2017. 'Cultural MegaEvents and The Enhancement of a City's Image: Differences Between Engaged Participants and Attendees', Journal of Policy Research in Tourism, Leisure and Events, Vol. 9, No. 2, pp. 129-151.

Undang-Undang Republik Indonesia Nomor 10 Tahun 2009 Tentang Kepariwisataan.

Wirawan, K. 2015. Pariwisata Bersepeda dalam Mewujudkan Pariwisata Berkelanjutan di Sanur (tesis). Denpasar: Universitas Udayana.

\section{Profil Penulis:}

Ida Rahayu merupakan mahasiswa Magister Pariwisata di Universitas Udayana Angkatan 2015. Saat ini beliau bekerja sebagai dosen di Universitas Internasional Batam. Beliau menamatkan pendidikan Sarjana di Sekolah Tinggi Pariwisata Ambarukmo Yogyakarta. Pernah bekerja di Hotel Harmoni Batam dan juga Dinas Pariwisata dan Kebudayaan Kota Tanjungpinang. 